\title{
Functions of Pointing by Humans, and Dogs' Responses, During Dog-Human Play Between Familiar and Unfamiliar Players
}

\author{
Robert W. Mitchell*, Emily Reed, and Lyndsey Alexander \\ Department of Psychology, Eastern Kentucky University \\ *Corresponding author (Email: robert.mitchell@eku.edu)
}

Citation - Mitchell, R.W., Reed, E., \& Alexander, L. (2018). Functions of pointing by humans, and dogs' responses, during dog-human play between familiar and unfamiliar players. Animal Behavior and Cognition, 5(2), 181-200. https://doi.org/10.26451/abc.05.02.01.2018

\begin{abstract}
Although much research focuses on human index finger pointing to hidden items for dogs in experimental settings, there is little research about human pointing in naturalistic interactions. We examined human pointing to dogs during 62 dog-human play interactions, spanning 4.8 hours of videotape, to determine the functions of human pointing and dogs' responses to that pointing. Participants were 26 humans and 27 dogs. Humans played with their own $\operatorname{dog}(\mathrm{s})$ and, almost always, an unfamiliar dog. Seventeen people (16 players and one passerby) pointed for 20 dogs a total of 101 times (once with a foot) during 26 interactions. Most (49.5\%) points were toward an object (almost always a ball), to direct attention or action toward the object; $36.6 \%$ were to the ground in front of the (almost always familiar) pointer, directing the dog to come, and/or drop a ball the dog held, here; $10.9 \%$ directed the dog toward the designated player and/or play area; and 3.0\% directed the dog to move away from a ball the dog had dropped. Humans almost always pointed such that the dog could see the point (92.1\%), and pointed more with their own than with an unfamiliar dog. Dogs responded appropriately (i.e., did what the pointer requested) for only $24.7 \%$ of the visible points, more often for points to the ground than for points to objects. The proportion of dogs' appropriate responses to visible points was similar for both familiar (30\%) and unfamiliar (18\%) humans. Six dogs who responded appropriately to some points resisted responding appropriately to others. Future research should examine non-object directed uses of pointing with dogs and their responses in naturalistic and experimental settings, and experimentally assess diverse explanations, including resistance, when dogs and other animals fail standard pointing tasks.
\end{abstract}

Keywords - Dogs, Humans, Pointing, Play, Resistance, Self-control

Numerous studies followed from the discovery (Hare, Call, \& Tomasello, 1998; Hare \& Tomasello, 1999; Miklósi, Polgárdi, Topál, \& Csányi, 1998) that dogs can use human pointing by index finger or other means to decide which one of two containers has a hidden food or toy inside (e.g., Dorey, Udell, \& Wynne, 2009, 2010; Gásci, Kara, Belényi, Topál, \& Miklósi, 2009; Gásci, McGreevy, Kara, \& Miklósi, 2009; Hare, Brown, Williamson, \& Tomasello, 2002; Hare et al., 2010; Helton \& Helton, 2010; Kraus, van Waveren, \& Huebner, 2014; MacLean, Herrmann, Suchindran, \& Hare, 2017; Malassis \& Delfour, 2015; Miklósi \& Soproni, 2006; Mulcahy \& Hedge, 2012; Udell, Dorey, \& Wynne, 2008, 2010a; Udell, Ewald, Dorey, \& Wynne, 2014; Wobber, Hare, Koler-Matznick, Wrangham, \& Tomasello, 2009; Soproni, Miklósi, Topál, \& Csányi, 2001; Wynne, Udell, \& Lord, 2008; Zaine, Domeniconi, \& Wynne, 2015). Although there are numerous variations, typically a dog's attention is drawn to the two 
containers, and a human's point indicates which is the correct one to choose. In most of these studies, the purpose of the research is to see if, and how often, dogs responded appropriately to pointing in this very circumscribed context in which a reward was hidden.

Most researchers agree that many dogs are often very good at responding appropriately to pointing (that is, doing what the pointer requests by the pointing) in this context, with dogs seeming to view pointing as a strong suggestion, sometimes a command, for how to act in the two-choice situation (Scheider, Kaminski, Call, \& Tomasello, 2013; Szetei, Miklósi, Topál, \& Csányi, 2003). However, many dogs are also influenced by other factors, such as side preferences, earlier reinforcement, early experience with little to no human interaction, or knowledge of the location of the reward, such that they fail to respond appropriately to pointing (D’Aniello et al., 2017; Gásci, Kara, et al., 2009; Petter, Musolino, Roberts, \& Cole, 2009; Udell et al., 2008). Questions remain for some researchers as to whether dogs are inherently better than, or as good as, wolves (Udell et al., 2008; Virányi et al., 2008), apes (Hopkins, Russell, McIntyre, \& Leavens, 2013; Kirchhofer, Zimmerman, Kaminski, \& Tomasello, 2012), or other animals, including humans (Lakatos, Soproni, Dóka, \& Miklósi, 2009; Miklósi, Pongrácz, Lakatos, Topál, \& Csányi, 2005; Smet \& Byrne, 2014) at interpreting pointing.

Surprisingly, there is no research on what people point to and how dogs react to this pointing in naturalistic settings, though some studies note that naturalistic pointing is used to teach dogs skills for hunting and object location (Hare et al., 1998), or during play with humans (Mitchell \& Thompson, 1991; Rooney, Bradshaw \& Robinson, 2001). It is remarkable, given the extent of research on human pointing to dogs, that we have almost no knowledge of the functions of points that dogs experience in normal life and how appropriately dogs respond to the requests of pointers.

We examined human pointing to familiar and unfamiliar dogs during dog-human play interactions. In Experiment 1, we examined the frequencies and functions of human pointing for dogs during play. In Experiment 2, we examined these dogs' responses to the diverse types of human pointing during dog-human play. The same humans, dogs, and materials were used in both experiments.

\section{Experiment 1: Frequencies and Functions of Human Pointing During Dog-Human Play}

Humans point with a diversity of hand and other gestures. Apparently humans commonly point using a finger toward an object or location, but also point using the whole hand, foot, lips, and other gestures in the direction of a desired object and/or location (e.g., Enfield, 2001; Hauser, Comins, Pytka, Cahill, \& Velez-Calderon, 2011; Lakatos et al., 2009; Leavens, 2012; Leavens \& Hopkins, 1999; Miklósi \& Soproni, 2006; Wilkins, 2013), and there is variation in pointing gestures (or lack thereof) across cultures (e.g., Leavens, 2012; Wilkins, 2013).

The types of points used in pointing comprehension research with dogs and other animals are diverse, and there is little systematization across studies (Miklósi \& Soproni, 2006; Udell et al., 2010a). Although research on dogs' comprehension of pointing has examined the efficacy of odd or unique human gestures on dogs' responses, most such research has examined pointing by the use of an extended index finger (Dorey et al., 2009). Consequently, we focused on index finger pointing.

In research examining dogs' responses to human pointing, someone directs the dog's attention toward two containers, one of which usually contains food, and then the pointer points toward the baited container. While common in research, such a context is unlikely in non-research interactions between dogs and people. In naturalistic settings, the dog's attention is not, prior to the point, directed toward two things, one of which the point discriminates. Unless the dog is being trained to respond to pointing, the point may be the only salient attention-directing behavior the dog experiences. Indeed, if a point is to an object, the pointer is likely to have pointed because the dog was not responding appropriately to the object, or was unsure of its location.

Unfortunately, no studies examined in detail the evidence of spontaneous (unrequested) human pointing for dogs or other animals besides humans. Spontaneous human pointing for and by interacting mothers and their young children (Ayala \& López, 2011), perhaps comparable to pointing for animals, serves a diversity of functions: to show something to someone (declarative pointing, the most frequent 
function for both mothers and children), to request that someone give or bring an object to the pointer (imperative pointing), to request an action (other than giving or bringing an object), to inform someone about the location of an object, and to request that someone assist the pointer in a task. Other research suggests 18 functions of human pointing (Leavens, 2012), 12 of which chimpanzees share, and four of which are relevant to the present study: to draw attention to an entity, to request/demand someone to act on an object, to request repositioning of a social partner, and to deceive.

As noted, spontaneous human pointing occurs with dogs in play (Mitchell \& Thompson, 1991, Rooney et al., 2001). People sometimes use points in play to direct a dog's attention away from a desired object and toward another object (Mitchell \& Thompson, 1991). Pointing may also be a "play signal," in the sense that pointing in a play context may be an "action . . . used by dog owners with the apparent intention of initiating or increasing the intensity of dog-human play" (Rooney et al., 2001, p. 717). However, only six of 21 owners in Rooney et al. pointed in play with their dog (and points were infrequent among these) and dogs generally did not playfully respond at all or consistently to pointing, such that pointing is not a strikingly effective signal to initiate or increase the intensity of play across familiar dog-human play partners. Similarly, laughter, also proposed as a potential play signal to dogs during play (Rooney et al., 2001), seems ineffective (Mitchell \& Sinkhorn, 2014). As Rooney et al. note, "humans often use ineffective signals" during dog-human play (p. 718). Prior to enacting the current study, it was unknown if people unfamiliar with a dog will point during play. The purpose of Experiment 1 was to gain knowledge of how (and how frequently) humans use pointing when interacting with familiar and unfamiliar dogs in a naturalistic context: dog-human play.

We anticipated that human players would point; that humans would be attentive to their dog's attention, pointing such that their points were visible; and that some points would be directed toward objects. We examined whether familiarity influenced the frequency and types of pointing, and whether the frequency of pointing in this study differed from that in Rooney et al. (2001).

\section{Methods}

Participants. Participants were 26 dog owners ( 9 males, 17 females) who participated in a study on dog-human play; subjects were 27 dogs. Participants agreed to be videotaped playing with their own and another unfamiliar dog and to have their own dog videotaped while playing with another person. All participants were informed that the study concerned how people and dogs play when they are and are not familiar with each other, and participants agreed that their dog was playful and friendly to strangers. Pointing was not mentioned, as play was the object of the study. Convenience and snowball sampling were used: participants were asked to participate when observed with their dog or were asked by someone who knew them to be dog owners. On average, owners had owned their dog for over four years; the minimal length of ownership was four months. Of the dogs who experienced points, eight were retrievers (four Golden, three black-haired, one Labrador), four were mutts (three were collie mixes, one of these with St. Bernard; and one was a German shepherd mix), and there were one of each of the following: Akita, Chow Chow, Cocker spaniel, fox terrier, husky, miniature poodle, German shepherd, and Portuguese water dog. All except the poodle were medium- to large-sized dogs.

Materials. Play occurred outside, in large areas, either on open areas on campus (14 owners), or in large fenced backyards comprising approximately 50 - 100 square meters (12 owners). Players were provided with new, unused objects for each session: a standard yellow and orange tennis ball, a piece of rope $(\sim 1 \mathrm{~m})$ and two rags (one purple, one yellow, each $\sim 0.07 \times 1 \mathrm{~m}$ ) were available to play with. (When dogs arrived with a ball, it was taken and hidden from them.) The individuals interacting with the dogs were asked to begin the play interaction by tossing the ball, but were told they could do whatever they wanted for as long as they wished, and could stop whenever they wished. We call the person asked to play with a dog in a given interaction the designated player.

Design and procedure. Participants were told that their interaction would be videotaped up until a short while after it ended to quell their anxiety when they continued to be filmed after they indicated that their interaction was over; this post-play interaction lasted no more than $30 \mathrm{~s}$. For all interactions, the 
researcher videotaping the interaction was present in the play area, and tried to capture the interaction, sometimes scanning back and forth between human and dog when they were separated or increasing the field of focus. The dog's owner was also present when the designated player was unfamiliar, to avoid upsetting the dog, but the owner was told not to interact. For interactions filmed in an open area, numerous people passed by during filming; one such passerby pointed, and was included in the study. The study, conducted in the early 1980s, was approved by the university's IRB, and participants received $\$ 10$ for participating. For more information about the methodology see Mitchell (1987).

To allow for direct comparisons between familiar and unfamiliar dog-human pairs, we had owners A and B play with their own and the other person's dog. Thus, owner A played with A's dog and (separately) B's dog, and owner B played with B's dog and (separately) A's dog. All players in an AB group played in the same location. We videotaped 12 such AB groups, resulting in 48 dog-human play interactions (24 pairings of each person with his/her dog, and 24 pairings of the same people with an unfamiliar dog). Within the $\mathrm{AB}$ groups, eight owners played with the unfamiliar dog first, and 16 with their own dog first. AB groupings allow for statistical comparison of dog owners' points between familiar and unfamiliar dogs. We also videotaped 14 more dog-human play interactions, most including owners and dogs used in $\mathrm{AB}$ groups. Thus, some owners played with their own dog more than once, or played with more than one unfamiliar dog. Table 1 details the number of sessions in which each owner and dog participated. For one $\mathrm{AB}$ pair (pair $\mathrm{C} 2$ in Table 1), the owner persistently failed to follow instructions not to interact while her dog played with the designated (unfamiliar) player. Because we were interested in what people pointed to and how dogs responded to pointing, we examined all interactions.

All $4.8 \mathrm{hrs}$ of videotape were copied onto DVDs and time stamped for hour, minute, and second. Interactions averaged $4.7 \mathrm{~min}$, with a range from $2.3 \mathrm{~min}$ to $18.6 \mathrm{~min}$.

Reliability and coding. One researcher recorded all points, writing down when points occurred, who was playing, the context, the dog's response if any, and what was pointed to by the participant. This coder was knowledgeable about the research questions. A second coder, unaware of the research questions, was trained to detect points on the first hour of recorded data, and then independently coded the rest of the interactions. If neither coder detected a point during a session, this counted as one agreement that no point had occurred during that session. Percent agreement was calculated by the number of agreements divided by the sum of the number of agreements and disagreements. The two coders obtained $81 \%$ agreement on their independent assessments of points; they subsequently resolved disagreements by observing the disputed interaction, discussing the coded data, and making a joint decision. Although we calculated Cohen's kappa $(.515, p<.001)$, kappa values are not informative here (or elsewhere in our reliability) because they are influenced by the infrequency of occurrence of one type of observation in comparison to another (see Viera \& Garrett, 2005), which occurred in our data. The low Kappa value is also not surprising because coders were looking for a rare, often quick behavior over a several-hour-long time span.

The two coders subsequently independently assessed all points for approximately how long they were expressed $(r=.83, p<.001)^{1}$, whether or not the dog saw the point (90\% agreement), what the person pointed with $(100 \%)$, and what the person pointed toward $(95 \%)$. Percent agreement was calculated by the number of agreements divided by the sum of the number of agreements and disagreements. As with reliability for coding of points, coders settled disagreements by observation, discussion, and joint decision. Note that reliability for utterances and actions during play are presented in earlier research (Mitchell, 1987; Mitchell \& Thompson, 1990, 1991).

Points were differentiated into whether they occurred together in bouts, or alone (single). Points occurred in bouts if there was more than one point in relation to the same objective (e.g., "do this to that ball there"). In a bout, most points occurred within a few seconds of each other; the maximum time between points in a bout was 12s. Bouts occurred, of course, because the dog failed to respond appropriately to points prior to the bout's final point, to which it may or may not have responded appropriately. A single point (not in a bout), or a bout of points, is called an episode.

\footnotetext{
${ }^{1}$ The length of time a point lasted was coded as the approximate number of seconds it lasted, or as $0.5 \mathrm{~s}$ if it lasted $<1 \mathrm{~s}$.
} 
Table 1

Number of Points per Session and of Appropriate Responses (AR) to these Points during Dog-Human Play Interactions with Familiar and Unfamiliar Dogs

\begin{tabular}{|c|c|c|c|c|c|c|}
\hline \multirow[t]{2}{*}{ Human of pair } & \multicolumn{2}{|c|}{ \# of Sessions } & \multicolumn{2}{|c|}{ \# Points per Session } & \multicolumn{2}{|c|}{ \# AR Per Session } \\
\hline & Familiar & Unfamiliar & Familiar & Unfamiliar & Familiar & Unfamiliar \\
\hline A1 & 2 & 1 & 2,2 & 0 & 1,1 & -- \\
\hline A2 & 2 & 1 & $0,0[1]$ & 0 & [1] & -- \\
\hline $\mathrm{C} 1$ & 2 & 1 & 1,0 & 1 & 0 & 0 \\
\hline $\mathrm{C} 2$ & 1 & 1 & $1[17]$ & 2 & $1[1]$ & 0 \\
\hline D1 & 1 & 1 & 4 & 0 & 0 & -- \\
\hline D2 & 1 & 1 & 3 & 1 & 0 & 0 \\
\hline E1 & 1 & 1 & 10 & 0 & 2 & -- \\
\hline E2 & 1 & 1 & 3 & 0 & 1 & -- \\
\hline $\mathrm{F} 1$ & 2 & 1 & 0,0 & 0 & -- & -- \\
\hline $\mathrm{F} 2$ & 1 & 1 & 6 & 0 & 1 & -- \\
\hline G1 & 1 & 1 & 1 & 0 & 0 & -- \\
\hline G2 & 1 & 1 & 0 & 0 & -- & -- \\
\hline H1 & 1 & 1 & $5[1]$ & 0 & $0[0]$ & -- \\
\hline $\mathrm{H} 2$ & 1 & 1 & 0 & 0 & -- & -- \\
\hline I1 & 1 & 1 & 0 & $0\{1\}$ & -- & $-\{0\}$ \\
\hline $\mathrm{I} 2$ & 3 & 1 & $3,4,8$ & 0 & $3,3,3$ & -- \\
\hline $\mathrm{J} 1$ & 1 & 1 & 1 & 0 & 0 & -- \\
\hline $\mathrm{J} 2$ & 1 & 1 & 0 & 0 & -- & -- \\
\hline K1 & 1 & 1 & 0 & 0 & -- & -- \\
\hline K2 & 1 & 1 & 3 & 2 & 0 & 0 \\
\hline L1 & 3 & 1 & $0,0,0$ & 0 & -- & -- \\
\hline L2 & 1 & 1 & 5 & 1 & 3 & 1 \\
\hline M1 & 1 & 1 & 0 & 0 & -- & -- \\
\hline M2 & 1 & 1 & 2 & 10 & 0 & 1 \\
\hline Human C2, $2^{\text {nd }}$ Dog & 1 & & 0 & & -- & \\
\hline$X$ & 1 & & 0 & & -- & \\
\hline Human D1, Dog X & & 1 & & 0 & & -- \\
\hline$Y$ & 1 & & 0 & & -- & \\
\hline Human $Y$, Dog I2 & & 1 & & 0 & & -- \\
\hline Human I2, Dog $Y$ & & 1 & & 0 & & -- \\
\hline Total & 35 & 27 & 64 [19] & $17\{1\}$ & 21 & 2 \\
\hline
\end{tabular}

Notes: AB pairs are marked by the same initial letter followed by 1 or 2 (e.g., A1 and A2 are AB pairs); if more than one session occurred, the first session noted is the one used in the AB group. Thus, the unfamiliar dog for human A1 is the dog in pair A2, and vice versa. Italicized entries are not included in AB pairs. Square brackets [ ] indicate points by an owner to his or her own dog just before (A2) or during $(\mathrm{C} 2, \mathrm{H} 1)$ the dog's interaction with the unfamiliar player. Curly brackets \{\} indicate a point by a passerby during the interaction between the owner and her own dog. 


\section{Results}

One hundred and one points were observed (see Table 1) across 67 episodes. One person (playing with his own dog) pointed once with his foot; the rest of the points used the index finger on the right $(n=$ $72)$ or left $(n=27)$ hand, or both $(n=1)$. For this last double point (which counted as one point), the man simultaneously pointed for $1 \mathrm{~s}$ with both index fingers extended, and continued pointing with the right index finger for two more seconds. Most (78) points lasted (approximately) 1s or less; 18 lasted 2-3s, and five lasted 5-7s. Forty-four points were single points; 57 points occurred in 23 bouts of pointing (see Table 2).

Table 2

Number of Points Directed Toward Particular Dogs, Number of which are Single Points or in Bouts of Pointing, Number of Points Dogs Responded Appropriately to, and Percent of Successful (Appropriate) Responses to Visible Points

\begin{tabular}{|c|c|c|c|c|c|c|}
\hline Dog & \# Points & $\begin{array}{c}\text { \# Single } \\
\text { Points }\end{array}$ & $\begin{array}{l}\text { \# Bouts of } \\
\text { Points }\end{array}$ & \# Points Per Bout & $\begin{array}{l}\text { \# Appropriate } \\
\text { Response }\end{array}$ & $\begin{array}{c}\text { Percent } \\
\text { Successful }\end{array}$ \\
\hline I1 & 1 & 1 & 0 & -- & 0 & 0 \\
\hline $\mathrm{G} 2$ & 1 & 1 & 0 & -- & 0 & 0 \\
\hline $\mathrm{J} 1$ & 1 & 1 & 0 & -- & 0 & 0 \\
\hline $\mathrm{K} 1$ & 2 & 2 & 0 & -- & 0 & 0 \\
\hline M2 & 2 & 2 & 0 & -- & 0 & 0 \\
\hline K2 & $3 *$ & $3 *$ & 0 & -- & 0 & 0 \\
\hline $\mathrm{C} 1$ & 3 & 1 & 1 & 2 & 0 & 0 \\
\hline D2 & $3 * * *$ & $1 *$ & 1 & $2 * *$ & -- & -- \\
\hline D1 & 5 & 2 & 1 & 3 & 0 & 0 \\
\hline $\mathrm{H} 2$ & 6 & 4 & 1 & 2 & 0 & 0 \\
\hline A2 & 1 & 1 & 0 & -- & 1 & 100 \\
\hline L1 & 1 & 1 & 0 & -- & 1 & 100 \\
\hline E2 & 3 & 1 & 1 & 2 & 1 & 33.3 \\
\hline F2 & 6 & 4 & 1 & 2 & 1 & 66.7 \\
\hline M1 & 10 & 0 & 3 & $2,3,5$ & 1 & 10.0 \\
\hline A1 & 4 & 0 & 2 & 2,2 & 2 & 50.0 \\
\hline E1 & $10 *$ & $4 *$ & 2 & 2,4 & 2 & 22.2 \\
\hline $\mathrm{C} 2$ & $19 * * *$ & $7 * *$ & 5 & $2,2,2,3,3 *$ & 2 & 12.5 \\
\hline L2 & 5 & 3 & 1 & 2 & 3 & 60.0 \\
\hline I2 & 15 & 5 & 4 & $2,2,3,3$ & 9 & 60.0 \\
\hline Total & 101 & 44 & 23 & 57 & 23 & Mean $=24.11$ \\
\hline
\end{tabular}

Notes. Asterisks indicate that one (*), two (**), or three $(* * *)$ of these points were not visible to the dog. Percent success is the number of visible points appropriately responded to divided by the number of visible points.

Sixteen (61.5\%) players pointed at least once, as did one passerby. People pointed for $20(74.1 \%)$ dogs. Out of the 62 dog-human interactions, designated players pointed 81 times in 24 interactions. Three owners pointed 19 times in three interactions when their dog was playing with the unfamiliar designated player: 17 points by one woman and one by a man occurred during their dog's interaction with the designated unfamiliar player, and one point by a woman occurred on the way to the play area for her dog's interaction with the designated unfamiliar player. We included all of these in our general analyses, as our concern was to examine what people pointed to and the function of their pointing, as well as dogs' responses to pointing; however, none of these are included in comparisons using the 48 interactions resulting from the $\mathrm{AB}$ groups, which include only points by designated players in an interaction.

The average number of points per interaction (including those by non-designated players) was 1.6 points $(S D=3.2$; range: $0-18$; median/mode $=0)$. The average number of points for the 27 interactions in which pointing occurred was 3.7 points $(S D=3.9$; median $=2$; mode $=1)$. Among the designated players only, the average number of points per interaction was $1.4(S D=2.4$; range: $0-10$; median $/ \mathrm{mode}=0$; see Table 1). 
Generally, people were attentive to the dog's attention when pointing. All but eight of the 101 points appeared to be visible to the dog $(92.1 \%)$. All eight non-visible points were by owners playing with their own dog, and lasted 1s or less.

What was pointed to? Points had four global objectives: to get the dog to attend to, go to, and/or get an object; to get the dog to drop a ball on the ground in front of the person (or just come to the person); to direct the dog to the player and/or play area; and to direct the dog away from a dropped ball (see Table 3). Thus, points directed the dog in four ways: toward an object (to that), toward the ground at the pointer's feet (to here), toward the player/play area (to there), or away from a ball (away from here). The objective was discerned based on the context, including the person's speech. Most (46) points to an object were distal points; four were proximal. All points directed toward the player and play area or away from the ball were distal points, and all to the ground were proximal points. These data indicate that in naturalistic contexts dogs experience human pointing to more than just objects. People pointed in relation to only one of the four objectives in all but three interactions; in these, players pointed for their own dog to an object and either pointed to the ground (F2 and E1) or to the designated player or play area (C2).

Table 3

Number of Points and Number of Visible Points Directed toward Different Objectives, and Frequencies of Points and Appropriate Responses (AR) for Familiar and Unfamiliar Players

\begin{tabular}{|c|c|c|c|c|c|c|c|}
\hline Points Directed To: & Frequency & Percent & $\begin{array}{c}\text { \# Points to } \\
\text { Familiar }\end{array}$ & $\begin{array}{l}\text { \# Points to } \\
\text { Unfamiliar }\end{array}$ & $\begin{array}{c}\text { \# Visible } \\
\text { Points to Dog }\end{array}$ & $\begin{array}{c}\text { \# of } \mathrm{AR}^{*} \text { by } \\
\text { Familiar }\end{array}$ & $\begin{array}{l}\text { \# of AR* by } \\
\text { Unfamiliar }\end{array}$ \\
\hline To an Object: & 50 & 49.5 & 34 & 16 & 47 & 8 & 2 \\
\hline Ball & 46 & 92.0 & 32 & 14 & 43 & 6 & 2 \\
\hline Rags & 2 & 4.0 & 0 & 2 & 2 & -- & 0 \\
\hline Stick & 1 & 2.0 & 1 & 0 & 1 & 1 & -- \\
\hline Dog & 1 & 2.0 & 1 & 0 & 1 & 1 & -- \\
\hline To the ground & 37 & 36.6 & 36 & 1 & 36 & 12 & 0 \\
\hline To the player/area & 11 & 10.9 & 10 & 1 & 10 & 1 & 0 \\
\hline Away from an object & 3 & 3.0 & 3 & 0 & 0 & -- & -- \\
\hline Total & 101 & 100 & 83 & 18 & 93 & 21 & 2 \\
\hline
\end{tabular}

Points to objects. About half of the points were directed toward an object. Almost all indicated a ball for the dog to attend to and/or get. Two points in a bout indicated rags on the ground for the dog to get. One point (with a verbal "Look") indicated a recently thrown stick, and one indicated a passing dog, both directing the dog's attention to these.

Points to the ground. Most of the rest of the points were directed toward the ground in front of the person, directing dogs to move to that location and indicating that the dog should come to and, all but once, drop the ball at this spot. Twenty points (including the foot point) directed the dog to drop the ball the dog held here, meaning in front of the person, where the person pointed, and 17 directed the dog to come to the person; for 16 of these, the dog had the ball in its mouth.

Points to player/play area. Eleven points, all by people who were not designated players, were to the designated player or the play area (or both), directing the dog to go to the player and/or play area. One passerby pointed in the direction of a dog's owner, who was calling the dog as the dog wandered away from her, and said "That way." One owner pointed to the designated player before the play interaction began, saying "Go with Elizabeth, Yoyo"; the designated player was simultaneously inviting the dog to come to her. Another owner, in the midst of an interaction in which his dog was not playing with the designated player, pointed to the play area (where the player was) and said "Go ahead." During the play interaction in which the dog's owner interfered with the designated unfamiliar player who was attempting to play with the owner's dog, eight points in three bouts by the dog's owner were toward the play area and designated player. 
Points directing the dog away. Three points directed the dog away from the ball; none were visible to the dog. All three occurred between one dog and his owner (pair D2). The dog repeatedly chased the ball that his owner threw, and retrieved it to the owner's feet, but took a while to drop the ball from his mouth. While the dog held onto the ball, the owner petted the dog, and eventually the dog dropped and moved away from the ball. On two occasions, once with one point, the other time with a bout of two points, the owner (who never spoke) snapped his fingers and pointed away from the current location. Oddly, for all three points, it seems likely to have been evident to the owner that the dogs could not see the points, as the dog's attention was riveted on the ball he was moving away from, and the points were above the dog's head. These non-visible points occurred in what appeared to be a recurrent routine in their play, such that this pointing may have become ritualized.

Familiarity with the dog. Almost all points ( 83 out of 101 , or $82.2 \%)$ were by people toward their own dog (see Table 3). The rest $(n=18)$ were by people toward an unfamiliar dog, including the one by a passerby. Sixteen people pointed for their own dog at least once (61.5\% of 26 owners), and six of these people also pointed for an unfamiliar dog at least once (24.0\% of 25 unfamiliar players). Of the 25 people who interacted with both a familiar and an unfamiliar dog, nine never pointed with either dog, and 16 pointed at least once. Of these, they were more likely to point at least once for their own dog only $(n=$ $10)$ than to point at least once for the unfamiliar dog only $\left(n=0\right.$; $\operatorname{McNemar} \chi^{2}(1, N=10)=8.1, p=$ $.0044)$. If points from the 24 designated players when interacting in the $\mathrm{AB}$ groups are examined, owners pointed more often with their own $\operatorname{dog}(M=2.1, S D=2.5)$ than with an unfamiliar $\operatorname{dog}(M=0.7, S D=$ 2.1; Wilcoxon $T(n=24)=63, p=.02)$. On average, in AB groups, familiar players interacted $4.50 \mathrm{~min}$ per interaction $(S D=1.6)$, and unfamiliar players interacted $4.71 \mathrm{~min}$ per interaction $(S D=3.4 ; F(1,23)=$ $0.09, p=.77$ ). (Note that we examined whether order of play, with familiar or unfamiliar player first, influenced the frequency of pointing; it did not.)

Comparison to Rooney et al. Six of the 21 owners in Rooney et al. (2001) pointed for their dog during play, and 15 of 26 owners (when designated players) did in the current study. Proportionally more players pointed in the present study than in Rooney et al.'s study $\left(\chi^{2}(1, N=47)=3.99, p=.046\right)$, perhaps because our players, unlike theirs (p. 716), used objects. There were no differences in the rate of pointing (number of points per minute of interaction) for owners in $\mathrm{AB}$ groups playing with their own dog who pointed in the current study $(M=0.77, S D=0.68)$ and Rooney et al. $(M=0.40, S D=0.25$; MannWhitney $U(n=21)=31, p=.275)$.

\section{Discussion}

People commonly employed the extended index finger point during play with dogs as a communicative gesture, and sometimes did so for reasons other than to direct a dog's attention to an object's location. People about half the time pointed to an object, less frequently pointed to the ground (requesting the dog to come to the person and/or drop a ball), infrequently pointed to the player and/or play area for the dog to go to, and rarely pointed away from a dropped ball for the dog to move away from it. People clearly wanted dogs to respond appropriately to their pointing gestures, in that they almost always pointed such that their points were visible to the dog.

Familiarity increased the frequency of pointing, in that owners commonly pointed only for their own dog, and usually pointed more when playing with their own dog than with an unfamiliar dog. In $\mathrm{AB}$ pairs, owners pointed on average three times more for their own dog than for the unfamiliar dog. In part, this greater frequency of pointing likely resulted from dogs' generally greater playfulness with their owner than with the unfamiliar person (Mitchell \& Thompson, 1990). The lone owner who pointed more with the unfamiliar dog than with her own dog also threw the ball more often with the unfamiliar dog as he sometimes chased it; her own dog largely ignored the ball.

It appears that, when they point for dogs in play, people expect dogs to understand a variety of communicative intents - more than just directing their attention to an object, as in experimental studies. How well the dogs responded to human pointing during dog-human play is examined in Experiment 2. 


\section{Experiment 2: Dogs' Responses to Pointing During Dog-Human Play}

In studies of their understanding of pointing, dogs frequently respond to points to one of two containers by finding hidden food (or approaching a container), located in the direction of the point. Although on average groups of dogs that were tested showed above-chance performance in responding to pointing, many individual dogs (e.g., more than $50 \%$ of the subjects in Gásci, Kara et al., 2009) failed to achieve greater than chance selection of the pointed-to location, and many dogs (e.g., more than 50\% in Kirchhofer et al., 2012) failed to show interest in some aspects of testing, such that their understanding of pointing could not be assessed. Dogs' approaches to what is pointed to are taken as evidence that dogs understand pointing (but their failure to do so is not necessarily taken to indicate that they do not understand pointing). In these pointing contexts, the dogs' responses to pointing usually benefit them, in that the dogs can obtain a reward. Thus, although researchers emphasize that dogs do well in cooperative tasks involving pointing (e.g., Pettersson, Kaminski, Herrmann, \& Tomasello, 2011), these tasks usually are not themselves cooperative (in the sense of working together for a mutually beneficial aim) in that they directly benefit only the dog. Rather, the person's motives are helpful (rather than competitive) toward the dog. However, dogs respond to points even when it does not directly benefit them (e.g., to locate an unappetizing carrot: Pongrácz, Hegedüs, Sanurjo, Kövári, \& Miklósi, 2013).

Whether or not dogs respond to points as commands in the two-choice task seems to depend on the experiment. Some dogs appear to interpret points as commands (Kundey et al., 2010; Scheider et al., 2013; Takaoka, Maeda, Hori, \& Fujita, 2015), and some respond less definitively to points (Elgier, Jakovcevic, Mustaca, \& Bentosela, 2009; Petter et al., 2009; Scheider, Grassmann, Kaminski, \& Tomasello, 2011; Scheider et al., 2013), suggesting that perhaps these dogs understand that points can at times be ignored. When dogs knew which one of two containers contained food, they generally ignored points to the unbaited container, and were even more likely to ignore points in this context when transparent rather than opaque containers were used (Kundey et al., 2010).

\section{Play}

Dog-human play is an interesting context in which to examine pointing, because dogs and people appear to view play as an interaction in which "obedience" to human actions is not required (unless, of course, the "play" focuses on a dog's exhibiting obedience to trained commands or behaviors; Horowitz \& Hecht, 2016; Rooney, 1999). Usually, play allows the dog to "revel in being out of the person's control" (Mitchell, 2012, p. 375). Dogs and people can refuse to engage (momentarily or longer) in what the play partner is offering (e.g., a person may play object-keepaway, and the dog may stop chasing a ball), and dogs engage in activities (drop-away or quasi-retrieve the object) in which they obtain something and then, respectively, deposit it away from the play partner, or move it only partway to the partner (Mitchell \& Thompson, 1990, 1991). On the other hand, humans point to influence the dog to engage in activities that they perceive to be part of playing (Rooney et al., 2001).

\section{Familiarity}

Dogs' familiarity with a person influences their responses to his or her pointing. Though many dogs clearly have little trouble appropriately responding to the finger pointing gestures of familiar and unfamiliar humans (e.g., Hegedüs, Bálint, Miklósi, \& Pongrácz, 2013; Kundey et al., 2010), they follow their owner's points more often than an unfamiliar person's points when both are given simultaneously (Cook, Arter, \& Jacobs, 2014). Dogs appear to continue to respond more frequently to unbeneficial points from their owner than from a stranger, as it takes them longer to extinguish responses to the owner's than the stranger's points when these are directed toward one of two unbaited bowls. Dogs shown that the one of two bowls not pointed to was baited were quicker to learn to choose the bowl not pointed to when the owner consistently pointed to the unbaited bowl than when a stranger did (Elgier et al., 2009). Thus, findings are contradictory: dogs appear to more faithfully respond to their owner's points and do so 
longer than for a stranger's points, yet dogs can learn to use the points of the owner faster than those of a stranger to decide where to look for hidden food, even if the point is directed elsewhere.

In Study 2, we examined dogs' responses to the diverse types of human pointing during doghuman play described in Study 1, as well as the influence of familiarity on their responses. We anticipated that dogs would not respond appropriately to all points, and that dogs would more often respond appropriately to owners' points than to unfamiliar humans' points. To assess the idea that dogs' failure to respond appropriately to pointing resulted because they were distracted by things in their environment, we compared the appropriate responding of dogs in the open (likely more distracting) areas and the fenced areas, to determine whether or not distraction might explain these failures.

\section{Methods}

Reliability and coding. The two coders from Study 1 independently assessed whether or not the dog was aware of the presence of the object pointed to when it did not respond to points in an episode $\left(76 \%{ }^{2}\right)$, and whether or not the dog responded appropriately to the point, which was thus deemed successful ( $86 \%$ agreement). Percent agreement was calculated by the number of agreements divided by the sum of the number of agreements and disagreements. An appropriate response occurred when the dog's actions satisfied (at least minimally) the objective of a human's point (one of the four described in Study 1) that was visible to the dog. For example, if a person pointed to a ball, an appropriate response would include getting the ball, or moving to and attending to the ball; walking past the ball without attending to it would not be an appropriate response. Dogs' appropriate responses had to occur within a few seconds of the point. In a bout of pointing, only the final point could be counted as being responded to successfully, in that a bout occurs because the dog had not responded appropriately to the previous point(s). All appropriate responses occurred immediately or very shortly after the point, except for one that occurred $6-7 \mathrm{~s}$ after the point. As with earlier reliability, coders settled disagreements by observation, discussion, and joint decision. Note that reliability for dogs' actions during play are presented in earlier research (Mitchell, 1987; Mitchell \& Thompson, 1990, 1991).

\section{Results}

The frequency with which particular dogs acted appropriately to 101 points is presented in Tables 1,2 , and 3. Results below concern responses to the 93 visible points, unless otherwise noted. In total, dogs responded appropriately to only 23 points (18 of which lasted 1 s or less), which is $24.7 \%$ of 93 visible points, or $37.7 \%$ of 61 episodes with visible points. Of the 19 dogs for whom visible pointing occurred, nine dogs failed to respond appropriately to any points, and ten responded appropriately to at least one point. One dog responded appropriately to all nine episodes of pointing to the ground. The average success rate per dog (out of the total number of points visible to the dog) across the 19 dogs is $24.5 \%(S D=0.34)$. The average success rate per dog across the ten dogs who responded to at least one point was $46.5 \%(S D=0.34)$. Of the 39 visible points that occurred singly, dogs responded appropriately to $14(35.9 \%)$; of the 55 visible points that occurred during 22 bouts, dogs responded appropriately to nine final points: $16.4 \%$ of the points, or $40.9 \%$ of the bouts. All dogs but one who experienced pointing were medium- to large-sized dogs, which are better at responding to pointing than small dogs (Helton \& Helton, 2010), such that size was not an influence in the general failure to respond appropriately to pointing. Of the dogs who experienced no pointing, all but one were medium- to large-sized dogs.

Whether dogs more often responded appropriately or not can be determined by comparing, for each dog, the number of points (or episodes) responded to appropriately with the number of points (episodes) not appropriately responded. Dogs were more likely to show no appropriate responses to points

\footnotetext{
${ }^{2}$ The lower reliability here derived from one coder incorrectly evaluating whether the dog had seen the object just prior to the point, rather than evaluating whether the dog had been aware of the object recently (e.g., had dropped the object, had seen it thrown). This error became evident during joint observation and discussion.
} 
$(M=3.7, S D=3.5)$ than to show appropriate responses $(M=1.2, S D=2.1)$, Wilcoxon $T(n=18$ not including 1 zero difference) $=23.5, p=.007$. However, dogs were equally as likely to show no appropriate responses $(M=2.0, S D=2.0)$ or appropriate responses $(M=1.2, S D=2.1)$ across episodes, Wilcoxon $T$ ( $n=18$ not including 1 zero difference $)=47, p=.09$.

Failure and distraction. One might argue that our dogs failed, by contrast with dogs in an experimental context, because they were distracted by activities in their environment. Suggestive evidence is that dogs in experimental contexts showed better comprehension indoors (where presumably they were less distracted) than outdoors (Udell et al., 2008), but a recent study failed to replicate this finding, instead showing similar comprehension of pointing by dogs whether tested indoors or outside (Pongrácz, Gásci, Hegedüs, Péter, \& Miklósi, 2013). The distraction hypothesis can be examined in our study, in that the open environment on campus, where people ambled nearby, would be more distracting to dogs than the fenced backyard areas, which were closed off from such distractions.

To determine whether distractions influenced the dogs to be less responsive to pointing in the open than in the fenced backyard areas, we examined the effect of these environments on dogs' successful responding to all visible points. This method of determining success is the most appropriate here, as the hypothesized distraction would account for any non-response. First, we compared the percent of visible points appropriately responded to by each dog (only for dogs in AB groups) when playing with its owner in the two environments. Dogs responded appropriately with similar frequency (Mann-Whitney $U(n=$ $14)=20, p=.54)$ whether owners pointed in the fenced $(n=7, M=21.3 \%, S D=0.30)$ or open environment $(n=7, M=38.1 \%, S D=0.46)$. Second, we compared the percentage of visible points appropriately responded to by each dog (again, only for dogs in $A B$ groups) when playing with the familiar or unfamiliar player combined. Dogs responded appropriately with similar frequency (MannWhitney $U(n=17)=33, p=.84)$ whether players pointed in the fenced $(n=10, M=26 \%, S D=0.13)$ or open environment $(n=7, M=31 \%, S D=0.14)$. Apparently dogs responded appropriately at similar levels in more and less distracting environments.

Responses to visible points with different functions. Dogs' responses to the four types of points described in Study 1 are presented in Table 3, and discussed below. All appropriate responses to points were by dogs to their owner's point, except for two appropriate responses by dogs (L1, M1) to an unfamiliar player (L2, M2) pointing to a ball.

Visible points to objects. Dogs responded appropriately to $18.2 \%$ of the 47 visible points. Six dogs responded appropriately in 10 episodes by moving to and/or getting a ball, directing their attention to a stick, or going to a passing dog.

Eleven dogs failed to respond appropriately in 21 episodes. Twenty episodes involved a ball, and one involved rags. Of the 33 unsuccessful points, in 28 cases the dog had recently seen or attended to the object that was pointed to by the human. Five of the episodes (seven points) to a ball occurred in the play interaction in which the owner $\mathrm{C} 2$ tried repeatedly to get her dog to play with the designated unfamiliar player; the dog seems likely to have been confused. In seven episodes (ten points) with other dogs, the dog stayed with or moved toward the pointer. In three episodes (four points), one dog jumped at and (if the man walked) followed near its owner's hand or arm as the person pointed; in three episodes (four points) the dog moved closer to or past the ball (one, J1, starting directly toward it, then veered away), but did not get close or pick it up; in two episodes (seven points) the dog moved away from the ball; and for one point, the dog did not move toward the ball and instead sniffed the ground where she was. One gets the sense from many failures to respond that the dog was uninterested in playing with the ball, though the jumping dog tried to play tug o' war with the man's clothing on the pointing arm.

Visible points to the ground. Dogs responded appropriately to $33.3 \%$ of the 36 visible points. Three dogs responded appropriately following 12 episodes by moving close to or dropping the ball at the location specified. Five dogs failed to respond following 12 episodes. All but one failure occurred between familiar players. One dog enacted drop-away (getting the ball but depositing it away from the person). All the other dogs played object-keepaway with a ball.

Visible points to the player/play area. Dogs generally failed to respond appropriately to a point telling them to go to an unmarked location or person. Only one dog responded appropriately to one of the 
ten visible points during six episodes. The appropriate response occurred when the dog's owner, prior to play, pointed to the designated player and told the dog to go to her; the designated player also called to her. Two dogs failed to respond to their owners' points during four episodes, and one dog failed to respond to a passerby's point, all directing the dog to go to the player and/or play area.

Visible points to move away from a ball. There were no visible points directing the dog to move away from a ball. The two episodes comprising three points directing the dog away from the ball were with the pair D2 (see Experiment 1). Even though he could not see the points, the dog acted in concert with the owner's points in that he backed away from the ball he had dropped at the owner's feet.

Familiarity. To determine whether familiarity with the dog increased appropriate (successful) responding to visible points, we examined only those designated players in $\mathrm{AB}$ groups with points visible to the dog during an interaction. This included 14 dogs interacting with their owner, and six dogs in interaction with an unfamiliar person. ${ }^{3}$ We used three measures of success within each interaction: the number of visible points that the dog responded to appropriately, the percentage of the total number of visible points that were responded to appropriately, and the percentage of episodes of visible points that were responded to appropriately. Although interacting with familiar dogs produced more successful points (as well as more points) than interacting with an unfamiliar dog for all three measures, none of the measures showed statistically significant differences in successfully responding to pointing based on familiarity: for the number of successful points, $M($ fam $)=.93, S D=1.14 ; M($ unfam $)=.33, S D=0.52$; Mann-Whitney $U(n=20)=31, p=.32$; for percentage of successful total points, $M(\mathrm{fam})=30 \%, S D=$ $0.38 ; M($ unfam $)=18 \%, S D=0.40$; Mann-Whitney $U(n=20)=34, p=.18$; and for percentage of successful episodes, $M($ fam $)=38 \%, S D=.46 ; M($ unfam $)=22 \%, S D=0.40$; Mann-Whitney $U(n=20)=$ $34.5, p=.49$. Thus, points were similarly (un)successful for people when interacting with a familiar and unfamiliar dog.

\section{Discussion}

Dogs failed to respond to most visible points. They were particularly poor at responding to points directing them to go to the play area or player, better at responding to points to objects, and still better at responding to points to come (with a ball, usually) to the pointer and drop the ball nearby. Differences in distractions in enclosed vs. open environments, or in the familiarity of the pointer, did not influence the frequency of appropriate responding.

Given that we know from the two-choice studies that many dogs can understand pointing, particularly pointing to objects, the fact that some dogs responded appropriately to pointing in the play context is not surprising; what may be surprising is the failure of so many dogs (even dogs who responded to other points) to respond appropriately to pointing. Overwhelmingly, dogs failed to respond appropriately to most $(75.3 \%)$ of the visible points during dog-human play; just under $50 \%$ of the dogs who experienced at least one visible point failed to respond appropriately to any; and among the dogs who responded appropriately to at least one point, $67.1 \%$ of visible points were not appropriately responded to. Rooney et al. (2001) discovered similar patterns in their observations of pointing during play (though fewer players pointed in their study than in ours, perhaps because their players did not use objects). Given their overall low rates of responding in our study, dogs apparently do not view points in play as commands, and thus likely take into account the context when interpreting points. While playing, dogs can attempt to influence their co-player's actions to participate in social play activities enjoyed by the dogs (object-keepaway, tug o' war), and are allowed to ignore their human player's commands (and do so as well, apparently, when they no longer want to play).

\footnotetext{
${ }^{3}$ Because three dogs experienced visible points in both their familiar and unfamiliar interactions, their data for these interactions are not independent, such that comparing the success of points successfully responded to in the familiar and unfamiliar context is statistically problematic. However, although we violate the assumption of independence of observations, the Mann-Whitney $U$ test is used to get an idea as to whether people's success in pointing might have been influenced by their familiarity with the dog.
} 
If researchers had originally looked at pointing during play, rather than in the two-choice problem, they might have been surprised when dogs responded appropriately to pointing, rather than when they did not. They might also have attributed dogs' few appropriate responses to pointing to the context: in play, dogs are going to chase balls whether or not someone points to them, and dogs are going to drop balls on the ground in front of their human play partner whether this person points to the ground or not. Indeed, D2's action of moving away from the ball would have been coded as appropriate responding if the dog had seen his owner's points! Thus, one might want to argue that dogs' apparently appropriate responses to points were actually responses to something else - such as seeing a ball being thrown, or responding solely to the person's verbalizations. The one successful point by the owner to the designated player in which both owner's and designated player's verbalizations supporting the point's message occurred simultaneously with the point is potentially an example. But it is the only one: points were otherwise enacted because the dog was not responding in a way deemed appropriate to what was pointed to (e.g., the dog was not running after a thrown ball).

Similarly, although in our play interactions points were frequently accompanied by speech directing the dog to do what the point also directed the dog to do, it is important to emphasize that the dogs typically ignored people's vocal directives (which explains in part why talk to dogs during play is so repetitive: Mitchell, 2001, 2004; Mitchell \& Edmonson, 1999). An experimental study in which the influences of pointing and verbal commands were manipulated in play would be useful in teasing out their independent or mutual influences. One study examining the influence (outside of play) of spoken and gestured commands on water rescue dogs trained to respond to both indicates that these dogs generally followed gestures more than spoken words when presented either separately, or together indicating incongruent directives, though their responses varied with the sex of the dog and the context (D’Aniello, Scandurra, Alterisio, Valsecchi, \& Prato-Previde, 2016).

\section{General Discussion}

During play, people point to indicate to dogs what they want them to do; owners pointed more than unfamiliar players. During play, dogs may gain experience with human pointing to an object (to draw the dog's attention to it and/or ask the dog to retrieve the object), to the ground by the person's feet (to direct the dog to come to and likely drop a ball there), to the player and/or play area (to get the animal to interact with or go to the player), and away from a ball (to direct the dog to distance itself from a dropped ball). However, dogs generally failed to respond appropriately to human points during play, whether from their owner or an unfamiliar player. Dogs did respond to pointing from both familiar and unfamiliar people during play, did respond flexibly to human pointing (i.e., respond appropriately or not) in a context in which responding to human commands is not required, and did try to engage their human players with other activities (e.g., object-keepaway, tug o' war) when requested to act via pointing.

\section{Should We Ignore Dogs Who Do Not Respond Appropriately to Pointing?}

From the data reported here and elsewhere (Rooney et al., 2001), it is clear that dogs who understand human pointing may not respond to it during play, or may respond only somewhat. Hare et al. (2010) argued that, in assessing dogs' understanding of pointing, we should not include animals that do not respond at all to points. If this reasoning were applied to our data, we would use only those ten dogs who responded appropriately to at least one point of those visible. In this case, we have 23 visible points responded to appropriately out of 70 , such that only $32.9 \%$ of the points were appropriately responded to, with the average success rate of $46.5 \%$.

If the purpose of a study is to discover whether dogs as a species typically respond appropriately to pointing, then we need to include all dogs, even those who do not respond to pointing, to discern how typical the appropriate responding is. For example, if we hypothesize that domestication of dogs led them to understand human pointing even without any earlier experience of it (Hare et al., 2002, 2010), then we need to test a variety of dogs with and without experience of humans (Wynne et al., 2008), and we need 
to include all dogs, whether they respond to pointing or not, in our data set. Yet researchers who support the domestication hypothesis wish to restrict data sets to only those dogs who appropriately respond to pointing at least sometimes. For example, although Hare et al. (2010, p. e3) found it "surprising" that Udell et al. (2008) included a dog who "never made a single choice" in their data on pointing by dogs, it should not have been surprising: Udell et al. tested the domestication hypothesis of Hare et al. (2002) which describes comprehension of pointing as a species-wide characteristic of dogs derived exclusively from domestication. Numerous studies failed to include unresponsive dogs (e.g., Kirchhofer et al., 2012; Lazarowski \& Dorman, 2015; Maclean et al., 2017; Wobber et al., 2009). It is also problematic that although researchers testing the domestication hypothesis recognize that dogs with no human contact need to be tested (Riedel, Schumann, Kaminski, Call, \& Tomasello, 2008), they only test dogs who have previously experienced human contact (see discussion in Wynne et al., 2008). Supporters of the domestication hypothesis suggest that dogs without human contact may be cognitively impaired as a result, and thus are useless to examine for evidence in relation to the domestication hypothesis (Kaminski \& Nitzschner, 2013), effectively making the hypothesis untestable. If pointing comprehension is a species-wide characteristic of dogs, as the domestication hypothesis predicts, then theorists must explain why so many dogs fail to respond appropriately to pointing. Interestingly, acknowledging that dogs can understand points but resist these directives may offer such an explanation (see below).

If the purpose of a study is to discover whether or not dogs can respond to pointing, and if they do, how well they understand it, then only those dogs showing that they can respond appropriately to pointing should be tested. Any information provided from such studies, however, cannot be used to support claims about species-wide capacities of dogs. Similarly, failure to find pointing understanding in one set of dogs does not mean that dogs cannot understand pointing. The same is true for other animals: chimpanzees showed good to excellent performance on one task that required them to understand human pointing (Hopkins et al., 2013), but performed poorly on another somewhat similar task that also required them to understand pointing (Kirchhofer et al., 2012). It is evident that, in the right circumstances, chimpanzees have no trouble understanding human points, or, in fact, in pointing themselves (Leavens, 2004; Leavens, Hopkins, \& Bard, 2005; Lyn et al., 2014; cf Tempelmann, Kaminski, \& Liebal, 2013).

\section{Explaining Poor Performance}

It would be extremely surprising, given consistent claims that dogs generally understand (and thus respond appropriately to) pointing, that our sample happened to have a majority of dogs that did not understand pointing very well. As one reviewer noted, and we agree, there may be many explanations for the general failure of our dogs. We focus on one for which we can provide evidence. It seems to us likely that some dogs failed to respond appropriately, not because they did not understand what the pointer indicated (although this may be true for some of the dogs), but because they resisted the impulse to respond appropriately. As Bateson (1966/1987) noted, researchers need to be aware that an animal "may or may not choose to do 'right,' [i.e., do what is expected] even after he knows which [action] is right" (p. 386). Minimally, the fact that dogs responded to the final point in $41 \%$ of the bouts of pointing suggests that these dogs understood the pointing in the bouts all along, but did not act upon their understanding.

Resisting human pointing is not a particularly complex or remarkable activity. Researchers acknowledge that dogs sometimes resist, ignore, or otherwise refuse to act on pointing by humans (e.g., Kundey et al., 2010; Riedel et al., 2008; Scheider et al., 2013). It is well known that dogs can inhibit responding (Bray, MacLean \& Hare, 2014; Elgier et al., 2009; Petter et al., 2009; Scheider et al., 2011), an essential part of resisting. Dogs can also resist by withholding information. For example, when dealing with a competitive human who took the food that dogs knew to be hidden in one of two objects when the dogs indicated the food-containing object, some dogs refused to approach the objects (Kundey et al., 2010; Petter et al., 2009). Dogs playing with people may engage in resistance when they get a ball and drop it away from the person (drop-away), or start to retrieve a ball and then drop it only part of the way to a human player (quasi-retrieve), and some dogs engaged in refusals when they stopped chasing an object during a human's project of object-keepaway (Mitchell \& Thompson, 1990, 1991). Though 
resistance by animals to human directives has been only sporadically attended to by researchers (Mitchell, 1999; Nance, 2013; Patterson \& Linden, 1981; Philo \& Wilbert, 2000; Warkentin, 2009), the idea that animals resist human authority has a long history (Hribal, 2003, 2010). Given that dogs can resist human pointing in other contexts (e.g., Kundey et al., 2010; Petter et al., 2009), it would be surprising if they were unable to resist human directives during play, a context that typically provides freedom from obedience.

Resistance requires evidence that the dog understands what the pointer wants but chooses not to satisfy the pointer. To see if resistance is a potential explanation for some of our dogs' failures to respond appropriately to pointing, we examined their responses to visible points to see if they provided any evidence of resistance. Resistance was present when dogs either responded appropriately to some (minimally one) but not all visible points of a particular type, or began by responding appropriately to a visible point but then stopped. We found evidence for resistance for points to an object and to the ground. (Note that we excluded the interaction in which the owner $\mathrm{C} 2$ inappropriately interacted when the unfamiliar person was the designated player, as the dog was likely confused.)

Three dogs resisted points directing them toward a ball. After walking away with a thrown ball from the unfamiliar designated player, then retrieving a thrown ball, then dropping the ball away from the human, and then running directly up to a thrown ball but not picking it up, M1 responded appropriately only to the final point in a bout of two toward the ball by moving directly right up to it. However, M1 failed to approach the ball following eight other points to it. L2 went to get the ball for three single points, but failed to get the ball after a bout of two points to it near the end of the play session. J1 inhibited his response to his owner's single point. He moved momentarily in the direction of the pointed-to ball (during a point the owner held for 5s), but then turned away, looking away from the owner and the ball. He apparently comprehended the point as directing him toward the ball, as he started directly toward it, but then stopped from getting close to it (and thus was not coded as responding appropriately). This dog played by trying to get an object the person held or playing object-keepaway, rather than by retrieving a ball.

Three dogs resisted points to drop a ball near the pointer by not letting go of a ball. E1 dropped the ball on the ground on the second point to the ground in one bout (and picked up the ball on the fourth point to it in another bout), but he ignored three single points to the ground. A1 twice required two points to the ground before dropping the ball by his owner. $\mathrm{I} 2$ responded appropriately to drop the ball on the ground where his owner pointed for five single points and the final points of four bouts of two to three points to the ground, but failed to drop the ball in response to a total of six pre-final points in bouts. These dogs' appropriate responses provide evidence of understanding of pointing, and their failures to respond appropriately provide evidence of resistance to pointing.

\section{Implications}

Given the wide variety in responses to pointing of the two groups of nonhuman animals who have been tested extensively, dogs and chimpanzees (D'Aniello et al., 2017; Gásci, Kara, et al., 2009; Hare \& Tomasello, 2004; Hopkins et al., 2013; Kirchhofer et al., 2012; Leavens, 2004; Riedel et al., 2008), it is plausible that comprehension of pointing is not a skill that is present species-wide, but is one that seems to occur relatively easily among many dogs and chimpanzees when they are socialized with humans, and less easily when they are not (D'Aniello et al., 2017; Leavens et al., 2005; Udell et al., 2010a, b; though see Kirchhofer et al., 2012). The same seems likely to be true for other animals who understand pointing, like captive dolphins (Herman et al., 1999; Tschudin, Call, Dunbar, Harris, \& van der Elst, 2001) and dogs (Soproni et al., 2001) who had experience with human gestures but were not trained to use points as part of their repertoire (see Udell et al., 2010b).

Researchers also need to take seriously the idea of animals resisting their control in their assessment of animals' responses in studies of these animals' understanding of pointing and other cognitive phenomena (see further discussion in Appendix). Researchers generally ignore dogs who fail to respond to pointing, although some have been concerned to examine alternative explanations other than 
lack of understanding for poor performance in dogs (Gásci, Kara, et al., 2009; Plourde \& Fiset, 2013) and other species (Hopkins et al., 2013; Schmitt, Schloegl, \& Fischer, 2014). If we are to understand why dogs and other animals succeed or fail on pointing tasks, we need to examine more carefully those who fail as well as those who succeed, across diverse contexts (e.g., Kraus et al., 2014). Naturalistic studies can be helpful here, in that observers may detect issues and behaviors not attended to in experimental studies, which can then be examined experimentally.

\section{Acknowledgements}

We appreciate the assistance of the reviewers, Andrew Manson, Ellen Furlong, the staff at the Chevy Chase Animal Clinic in Lexington, Kentucky, Michelle Smith, and all the players.

\section{References}

Ayala, M. A. M., \& López, M. J. R. (2011). Functions of the pointing gesture in mothers and their 12 to 36 -monthold children during everyday activities. The Spanish Journal of Psychology, 14, 619-629.

Bateson, G. (1966/1987). Problems in cetacean and other mammalian communication. In G. Bateson (Ed.), Steps to an ecology of mind (pp. 364-378). Northvale, NJ: Jason Aronson Inc.

Bray, E. E., MacLean, E. L., \& Hare, B. A. (2014). Context specificity of inhibitory control in dogs. Animal Cognition, 17, 15-31.

Cook, A., Arter, J., \& Jacobs, L. F. (2014). My owner, right or wrong: The effect of familiarity on the domestic dog's behavior in a food-choice task. Animal Cognition, 171, 461-470.

D’Aniello, B., Alterisio, A., Scandurra, A., Petremolo, E., Iommelli, M. R., \& Aria, M. (2017). What's the point? Golden and Labrador retrievers living in kennels do not understand human pointing gestures. Animal Cognition, 20, 777-787.

D’Aniello, B., Scandurra, A., Alterisio, A., Valsecchi, P., \& Prato-Previde, E. (2016). The importance of gestural communication: A study of dog-human communication using incongruent information. Animal Cognition, $19,1231-1235$.

Dorey, N. R., Udell, M. A. R., \& Wynne, C. D. L. (2009). Breed differences in dogs ${ }^{4}$ sensitivity to human points: A meta-analysis. Behavioural Processes, 81, 409-415.

Dorey, N. R., Udell, M. A. R., \& Wynne, C. D. L. (2010). When do domestic dogs, Canis familiaris, start to understand human pointing? The role of ontogeny in the development of interspecies communication. Animal Behaviour, 79, 37-41.

Elgier, A. M., Jakovcevic, A., Mustaca, A. E., \& Bentosela, M. (2009). Learning and owner-stranger effects on interspecific communication in domestic dogs (Canis familiaris). Behavioural Processes, 81, 44-49.

Enfield, N. J. (2001). "Lip-pointing": A discussion of form and function with reference to data from Laos. Gesture, $1,185-212$.

Gásci, M., Kara, E., Belényi, B., Topál, J., \& Miklósi, Á. (2009). The effect of development and individual differences in pointing comprehension of dogs. Animal Cognition, 12, 471-479.

Gásci, M., McGreevy, P., Kara, E., \& Miklósi, Á. (2009). Effects of selection for cooperation and attention in dogs. Behavioral and Brain Functions, 5, 1-8.

Hare, B., Brown, M., Williamson, C., \& Tomasello, M. (2002). The domestication of social cognition in dogs. Science, 298, 1634-1636.

Hare, B., Call, J., \& Tomasello, M. (1998). Communication of food location between human and dog (Canis familiaris). Evolution of Communication, 2, 137-159.

Hare, B., Rosati, A., Kaminski, J., Bräuer, J., Call, J., \& Tomasello, M. (2010). The domestication hypothesis for dogs' skills with human communication: A response to Udell et al. (2008) and Wynne et al. (2008). Animal Behaviour, 79, e1-e6.

Hare, B., \& Tomasello, M. (1999). Domestic dogs (Canis familiaris) use human conspecific social cues to locate hidden food. Journal of Comparative Psychology, 113, 173-177.

\footnotetext{
${ }^{4}$ The published article includes this typo.
} 
Hare, B., \& Tomasello, M. (2004). Chimpanzees are more skillful in competitive than in cooperative cognitive tasks. Animal Behaviour, 68, 571-581.

Hauser, M. D., Comins, J. A., Pytka, L. M., Cahill, D. P., \& Velez-Calderon, S. (2011). What experimental experience affects dogs' comprehension of human communicative actions? Behavioural Processes, 86, $7-$ 20.

Hegedüs, D., Bálint, A., Miklósi, Á., \& Pongrácz, P. (2013). Owners fail to influence the choices of dogs in a twochoice, visual pointing task. Behaviour, 150, 427-443.

Helton, W. S., \& Helton, N. D. (2010). Physical size matters in the domestic dog's (Canis lupus familiaris) ability to use human pointing cues. Behavioural Processes, 85, 77-79.

Herman, L. M., Abichandani, S. L., Elhajj, A. M., Herman, E. Y., Sanchez, J. L., \& Pack, A. A. (1999). Dolphins (Tursiops truncatus) comprehend the referential character of the human pointing gesture. Journal of Comparative Psychology, 113, 347-364.

Hopkins, W. D., Russell, J., McIntyre, J., \& Leavens, D. A. (2013). Are chimpanzees really so poor at understanding imperative pointing? Some new data and an alternative view of canine and ape social cognition. PLoS One, 8, e79338.

Horowitz, A., \& Hecht, J. (2016). Examining dog-human play: The characteristics, affect, and vocalizations of a unique interspecific interaction. Animal Cognition, 19, 779-788.

Hribal, J. (2003). "Animals are part of the working class": A challenge to labor history. Labor History, 44, 435-453.

Hribal, J. (2010). Fear of the animal planet: The hidden history of animal resistance. Petrolia and Oakland, CA: CounterPunch and AK Press.

Kaminski, J., \& Nitzschner, M. (2013). Do dogs get the point? A review of dog-human communication ability. Learning and Motivation, 44, 294-302.

Kirchhofer, K. C., Zimmerman, F., Kaminski, J., \& Tomasello, M. (2012). Dogs (Canis familiaris), but not chimpanzees (Pan troglodytes), understand imperative pointing. PLoS One, 7(e30913), 1-7.

Kraus, C., van Waveren, C., \& Huebner, F. (2014). Distractable dogs, constant cats? A test of the distraction hypothesis in two domestic species. Animal Behaviour, 93, 173-181.

Kundey, S. M. A., De Los Reyes, A., Arbuthnot, J., Allen, R., Coshun, A., ...Royer, E. (2010). Domesticated dogs' (Canis familiaris) response to dishonest human points. International Journal of Comparative Psychology, 23, 201-215.

Lakatos, G., Soproni, K., Dóka, A., \& Miklósi, Á. (2009). A comparative approach to dogs' (Canis familiaris) and human infants' comprehension of various forms of pointing gestures. Animal Cognition, 12, 621-631.

Lazarowski, L., \& Dorman, D. C. (2015). A comparison of pet and purpose-bred research dog (Canis familiaris) performance on human-guided object-choice tasks. Behavioural Processes, 110, 60-67.

Leavens, D. (2004). Manual deixis in apes and humans. Interaction Studies, 5, 387-408.

Leavens, D. (2012). Pointing: Contexts and instrumentality. In K. Liebal \& S. Pika (Eds.), Developments in primate gesture research (pp. 181-197). Amsterdam: John Benjamins.

Leavens, D., \& Hopkins, W. D. (1999). The whole-hand point: The structure and function of pointing from a comparative perspective. Journal of Comparative Psychology, 113, 417-425.

Leavens, D., Hopkins, W. D., \& Bard, K. A. (2005). Understanding the point of chimpanzee pointing. Current Directions in Psychological Science, 14, 185-189.

Lyn, H., Russell, J. L., Leavens, D. A., Bard, K. A., Boysen, S. T., ...Hopkins, W. D. (2014). Apes communicate about absent and displaced objects: Methodology matters. Animal Cognition, 17, 85-94.

MacLean, E. L., Herrmann, E., Suchindran, S., \& Hare, B. (2017). Individual differences in cooperative communicative skills are more similar between dogs and humans than chimpanzees. Animal Behaviour, $126,41-51$.

Malassis, R., \& Delfour, F. (2015). Sea lions' (Zalophus californianus) use of human pointing gestures as referential cues. Learning and Behavior, 43, 101-112.

Miklósi, Á., Polgárdi, R., Topál, J., \& Csányi, V. (1998). Use of experimenter-given cues in dogs. Animal Cognition, 1, 113-121.

Miklósi, Á., Pongrácz, P., Lakatos, G., Topál, J., \& Csányi, V. (2005). A comparative study of the use of visual communicative signals in interactions between dogs (Canis familiaris) and humans and cats (Felis catus) and humans. Journal of Comparative Psychology, 119, 179-186.

Miklósi, Á., \& Soproni, K. (2006). A comparative analysis of animals' understanding of the human pointing gesture. Animal Cognition, 9, 81-93. 
Mitchell, R. W. (1987). Projects, routines, and enticements in interspecies play between familiar and unfamiliar dogs and people (unpublished PhD thesis). Clark University, Worcester, MA.

Mitchell, R. W. (1999). Deception and concealment as strategic script violation in great apes and humans. In S. T. Parker, R. W. Mitchell, \& H. L. Miles (Eds.), The mentalities of gorillas and orangutans (pp. 295-315). Cambridge, UK: Cambridge University Press.

Mitchell, R. W. (2001). Americans' talk to dogs during play: Similarities and differences with talk to infants. Research on Language and Social Interaction, 34, 182-210.

Mitchell, R. W. (2004). Controlling the dog, pretending to have a conversation, or just being friendly? Influences of sex and familiarity on Americans' talk to dogs during play. Interaction Studies, 5, 99-129.

Mitchell, R. W. (2012). Doing and saying in play between dogs and people. In M. DeMello (Ed.), Animals and society: An introduction to human-animal studies (pp. 374-376). New York: Columbia University Press.

Mitchell, R. W., \& Edmonson, E. (1999). Functions of repetitive talk to dogs during play. Society and Animals, 7 , 55-81.

Mitchell, R. W., \& Sinkhorn, K. (2014). Why do humans laugh during dog-human play interactions? Anthrozoös, 27, 235-250.

Mitchell, R. W., \& Thompson, N. S. (1990). The effects of familiarity on dog-human play. Anthrozoös, 4, $24-43$.

Mitchell, R. W., \& Thompson, N. S. (1991). Projects, routines, and enticements in dog-human play. In P. P. G. Bateson \& P. H. Klopfer (Eds.), Perspectives in ethology (Vol. 9, pp. 189-216). New York: Plenum Press.

Mulcahy, N. J., \& Hedge, V. (2012). Are apes tested with an abject object-choice task? Animal Behaviour, 83, 313321.

Nance, S. (2013). Entertaining elephants: Animal agency and the business of the American circus. Baltimore, MD: Johns Hopkins University Press.

Patterson, F., \& Linden, E. (1981). The education of Koko. New York: Holt, Rinehart \& Winston.

Petter, M., Musolino, E., Roberts, W. A., \& Cole, M. (2009). Can dogs (Canis familiaris) detect human deception? Behavioural Processes, 82, 109-118.

Pettersson, H., Kaminski, J., Herrmann, E., \& Tomasello, M. (2011). Understanding of human communicative motives in domestic dogs. Applied Animal Behaviour Science, 133, 235-245.

Philo, C., \& Wilbert, C. (2000). Animal spaces, beastly places: An introduction. In C. Philo \& C. Wilbert (Eds.), Animal spaces, beastly places: New geographies of human-animal relations (pp. 1-34). New York: Routledge.

Plourde, V., \& Fiset, S. (2013). Pointing gestures modulate domestic dogs' search behavior for hidden objects in a spatial rotation problem. Learning and Motivation, 44, 282-293.

Pongrácz, P., Gásci, M., Hegedüs, D., Péter, A., \& Miklósi, Á. (2013). Test sensitivity is important for detecting variability in pointing comprehension in canines. Animal Cognition, 16, 721-735.

Pongrácz, P., Hegedüs, D., Sanurjo, B., Kővári, A., \& Miklósi, Á. (2013). "We will work for you” - Social influence may suppress individual food preferences in a communicative situation in dogs. Learning and Motivation, 44, 270-281.

Riedel, J., Schumann, K., Kaminski, J., Call, J., \& Tomasello, M. (2008). The early ontogeny of human-dog communication. Animal Behaviour, 75, 1003-1014.

Rooney, N. J. (1999). Play behavior of the domestic dog Canis familiaris, and its effects upon the dog-human relationship (unpublished $\mathrm{PhD}$ thesis). University of Southampton, UK.

Rooney, N. J., Bradshaw, J. W. S., \& Robinson, H. (2001). Do dogs respond to play signals given by humans? Animal Behaviour, 61, 715-722.

Scheider, L., Grassmann, S., Kaminski, J., \& Tomasello, M. (2011). Domestic dogs use contextual information and tone of voice when following a human pointing gesture. PLoS One, 6, e21676.

Scheider, L., Kaminski, J., Call, J., \& Tomasello, M. (2013). Do domestic dogs interpret pointing as a command? Animal Cognition, 16, 361-372.

Schmitt, V., Schloegl, C., \& Fischer, J. (2014). Seeing the experimenter influences the response to pointing cues in long-tailed macaques. PLoS One, 9, e91348.

Siegel, S. (1956). Nonparametric statistics for the behavioral sciences. New York: McGraw-Hill.

Smet, A. F., \& Byrne, R. W. (2014). Interpretation of human pointing by African elephants: Generalisation and rationality. Animal Cognition, 17, 1365-1374.

Soproni, K., Miklósi, Á., Topál, J., \& Csányi, V. (2001). Comprehension of human communicative signs in pet dogs (Canis familiaris). Journal of Comparative Psychology, 115, 122-126. 
Szetei, V., Miklósi, Á., Topál, J., \& Csányi, V. (2003). When dogs seem to lose their nose: An investigation on the use of visual and olfactory cues in communicative context between dog and owner. Applied Animal Behaviour Science, 83, 141-152.

Takaoka, A., Maeda, T., Hori, Y., \& Fujita, K. (2015). Do dogs follow behavioral cues from an unreliable human? Animal Cognition, 18, 475-483.

Tempelmann, S., Kaminski, J., \& Liebal, K. (2013). When apes point the finger: Three great ape species fail to use a conspecific's imperative pointing gesture. Interaction Studies, 14, 7-23.

Tschudin, A., Call, J., Dunbar, R. I. M., Harris, G., \& van der Elst, C. (2001). Comprehension of signs by dolphins (Tursiops truncatus). Journal of Comparative Psychology, 115, 100-105.

Udell, M. A. R., Dorey, N. R., \& Wynne, C. D. L. (2008). Wolves outperform dogs in following human social cues. Animal Behaviour, 76, 1767-1773.

Udell, M. A. R., Dorey, N. R., \& Wynne, C. D. L. (2010a). What did domestication do to dogs? A new account of dogs' sensitivity to human actions. Biological Reviews, 85, 327-345.

Udell, M. A. R., Dorey, N. R., \& Wynne, C. D. L. (2010b). The performance of stray dogs (Canis familiaris) living in a shelter on human-guided object-choice tasks. Animal Behaviour, 79, 717-725.

Udell, M. A. R., Ewald, M., Dorey, N. R., \& Wynne, C. D. L. (2014). Exploring breed differences in dogs (Canis familiaris): Does exaggeration or inhibition of predatory response predict performance on human-guided tasks? Animal Behaviour, 89, 99-105.

Viera, A. J., \& Garrett, J. M. (2005) Understanding interobserver agreement: The kappa statistic. Family Medicine, $37,360-363$.

Virányi, Z., Gásci, M., Kubinyi, E., Topál, J., Belényi, B., ...Miklósi, Á. (2008). Comprehension of human pointing gestures in young human-reared wolves (Canis lupus) and dogs (Canis familiaris). Animal Cognition, 11, $373-387$.

Warkentin, T. (2009). Whale agency: Affordances and acts of resistance in captive environments. In S. E. McFarland \& R. Hediger (Eds.), Animals and agency: An interdisciplinary exploration (pp. 23-43). Leiden, The Netherlands: Brill.

Wilkins, D. (2013). Why pointing with the index finger is not a universal (in sociocultural and semiotic terms). In S. Kita (Ed.), Pointing: Where language, culture, and cognition meet (pp. 171-216). New York: Psychology Press.

Wobber, V., Hare, B., Koler-Matznick, J., Wrangham, R., \& Tomasello, M. (2009). Breed differences in dogs' (Canis familiaris) comprehension of human communicative signals. Interaction Studies, 10, 206-224.

Woodruff, G., \& Premack, D. (1979). Intentional communication in the chimpanzee: The development of deception. Cognition, 7, 333-362.

Wynne, C. D. L., Udell, M. A. R., \& Lord, K. A. (2008). Ontogeny's impact on human-dog communication. Animal Behaviour, 76, e1-e4.

Zaine, I., Domeniconi, C., \& Wynne, C. D. L. (2015). The ontogeny of human point following in dogs: When younger dogs outperform older. Behavioural Processes, 119, 76-85. 


\section{APPENDIX}

The data presented above concerning some dogs' resistance to pointing suggest that, when animals do poorly on a pointing task, they may be resisting the experimenter's points. For example, in the pointing task in Kirchhofer et al. (2012), a human pointed to one of two objects, and the chimpanzees tested generally selected one of the objects randomly in relation to the point, and then almost always gave this object to a human pointer. Given that we know that chimpanzees can understand pointing (e.g., Hopkins et al., 2013), their actions are rather strange: taken at face value, their actions suggest that they took the pointing to mean "get some item and give it to the pointer." Kirchhofer et al. propose that the chimpanzees' actions indicated either that they "fail to comprehend the referential intention itself —or else they do comprehend it, but they do not think it important for their current goal of getting the food" (p. 6) (even though it is). ${ }^{5}$ But before we can use an animal's failure to respond as expected as evidence of either a lack of comprehension of a signal or of the signal's reward value, it is essential to know whether animals can choose not to do what is expected (Bateson, 1966/1987). Although it is well known that chimpanzees can inhibit their responding (Woodruff and Premack, 1979), the possibility that their subjects resisted responding appropriately to pointing is unmentioned by Kirchhofer et al. Thus, it may be that, even though the chimpanzees understood what the experimenter intended and knew that offering the pointed-to object resulted in reward, they resisted responding as the experimenter requested, perhaps finding it more engaging not to do so or finding the testing boring. To determine whether chimpanzees chose to respond inappropriately, one might want to examine their facial expressions when providing the object to the experimenter, their eye gaze in relation to the object pointed to, and other aspects of the situation. In line with the resistance hypothesis, three of the 20 chimpanzees tested selected seven of the pointed-to objects in the first eight trials (see Kirchhofer et al., 2012, supplementary materials, Table S1), which is statistically significantly better than chance based on the binomial test $(p=.035)$, but then the same three chimpanzees selected only three of the pointed-to objects in the second eight trials. Oddly, the authors only acknowledged that choosing eight items correctly in the first eight trials, ${ }^{6}$ shown by some dogs (see supplementary materials, Table S2), is significantly different from chance based on the binomial test, but in fact seven or more correct choices out of eight are statistically significantly different from chance based on the binomial test (see Siegel, 1956). Still more oddly, in another publication including some of the same authors (Riedel et al., 2008) but concerning understanding of pointing by dogs, not chimpanzees, seven (or more) out of eight was considered to be statistically significant using a binomial test". Thus, although Kirchhofer et al. stated that "For the chimpanzee group, no subject chose the target object significantly differently from chance level," (p. 5) in fact for the first eight trials, three chimpanzees did. Their initially successful and subsequently poor performances in response to human pointing suggest that these chimpanzees, like some dogs in the current study, understood the human's points but resisted responding appropriately to them.

\footnotetext{
${ }^{5}$ There are, of course, other simpler possibilities; for example, the authors never tested for side preferences, present in some dogs (Gásci, Kara, et al., 2009); nor did they test for recent positive experiences with pointing, which influences dogs and apes to succeed more on subsequent pointing tasks (Hopkins et al., 2013; Plourde \& Fiset, 2013).

${ }^{6}$ The authors mistakenly presented a two-tailed test with the binomial test as appropriate when examining the probability of so many or more choices occurring by chance; actually, only a one-tailed test is appropriate.

${ }^{7}$ The authors mistakenly claimed to have used the two-tailed test, but seven (or more) out of eight would not have been significant using the two-tailed binomial test, but is significant using the appropriate one-tailed binomial test.
} 